\title{
FT-NIRS Coupled with PLS Regression as a Complement to HPLC Routine Analysis of Caffeine in Tea Samples
}

\author{
Najeeb Ur Rehman ${ }^{1}\left(\mathbb{D}\right.$, Ahmed Al-Harrasi ${ }^{1, *}$, Ricard Boqué ${ }^{2, *}$, Fazal Mabood ${ }^{3, *}$, \\ Muhammed Al-Broumi ${ }^{1}$, Javid Hussain ${ }^{3}$ and Saif Alameri ${ }^{3}$ \\ 1 Natural and Medical Sciences Research Center, College of Arts and Sciences, University of Nizwa, \\ P.O. Box 33, Nizwa 611, Oman; najeeb@unizwa.edu.om (N.U.R.); albroumi@unizwa.edu.om (M.A.-B.) \\ 2 Department of Analytical Chemistry and Organic Chemistry, University of Rovira I Virgilli, \\ 43071 Tarragona, Spain \\ 3 Department of Biological Sciences \& Chemistry, College of Arts and Sciences, University of Nizwa, \\ P.O. Box 33, Nizwa 611, Oman; javidhej@unizwa.edu.om (J.H.); 09690741@uofn.edu.om (S.A.) \\ * Correspondence: aharrasi@unizwa.edu.om (A.A.-H.); ricard.boque@urv.cat (R.B.); \\ mehboob@unizwa.edu.om (F.M.); Tel.: +96-82-5446-328; Fax: +96-8254-4661-2
}

Received: 20 April 2020; Accepted: 8 June 2020; Published: 24 June 2020

\begin{abstract}
Daily consumption of caffeine in coffee, tea, chocolate, cocoa, and soft drinks has gained wide and plentiful public and scientific attention over the past few decades. The concentration of caffeine in vivo is a crucial indicator of some disorders-for example, kidney malfunction, heart disease, increase of blood pressure and alertness - and can cause some severe diseases including type 2 diabetes mellitus (DM), stroke risk, liver disease, and some cancers. In the present study, near-infrared spectroscopy (NIRS) coupled with partial least-squares regression (PLSR) was proposed as an alternative method for the quantification of caffeine in 25 commercially available tea samples consumed in Oman. This method is a fast, complementary technique to wet chemistry procedures as well as to high-performance liquid chromatography (HPLC) methods for the quantitative analysis of caffeine in tea samples because it is reagent-less and needs little or no pre-treatment of samples. In the current study, the partial least-squares (PLS) algorithm was built by using the near-infrared NIR spectra of caffeine standards prepared in tea samples scanned by a Frontier NIR spectrophotometer (L1280034) by PerkinElmer. Spectra were collected in the absorption mode in the wavenumber range of 10,000-4000 $\mathrm{cm}^{-1}$, using a $0.2 \mathrm{~mm}$ path length and $\mathrm{CaF}_{2}$ sealed cells with a resolution of $2 \mathrm{~cm}^{-1}$. The NIR results for the contents of caffeine in tea samples were also compared with results obtained by HPLC analysis. Both techniques provided good results for predicting the caffeine contents in commercially available tea samples. The results of the proposed study show that the suggested FT-NIRS coupled with PLS regression algorithun has a high potential to be routinely used for the quick and reproducible analysis of caffeine contents in tea samples. For the NIR method, the limit of quantification (LOQ) was estimated as 10 times the error of calibration (root mean square error of calibration (RMSECV)) of the model; thus, RMSEC was calculated as $0.03 \mathrm{ppm}$ and the LOQ as $0.3 \mathrm{ppm}$.
\end{abstract}

Keywords: caffeine; tea samples; NIR spectroscopy; HPLC analysis; PLS regression

\section{Introduction}

The applications and advances of near-infrared spectroscopy (NIRS) for the rapid and simultaneous determination of several analytes-e.g., in the detection of adulterated samples, quantification of active ingredients in food samples and medicinal plants, as well as the discrimination of food samples-are 
well documented [1-8]. NIRS is one of the fastest spectroscopic techniques and usually needs no reagents and no pre-treatment of samples [9]. NIRS with partial least-squares (PLS) regression has been considered as a complementary procedure for quantitative analysis in food and agriculture products [10-13]. It has also been proven to be a powerful analytical device used in the nutritional, agricultural and pharmaceutical industries [14-16] due to its accuracy when calibrated against an efficient reference method [17].

The popularity of tea is increasing constantly due to its beneficial and fundamental medicinal properties [18-22]. The quality of tea is currently becoming very important due to its increasing consumption, and many national and international authorities are setting criteria for its quality control [23]. Some previous studies have demonstrated that tea has numerous beneficial effects for consumer health, including the reduction of cholesterol, antimicrobial and antioxidant properties, decrease in hypertension, and protection against cancer and cardiovascular disease [24,25]. Chen et al. (2006) studied a rapid method of tea identification in the NIR region using an FT-IR spectrophotometer coupled with the SIMCA (Soft Independent Modelling of Class Analogy) classification method, in which the different classes were modeled individually by a separate principal component (PC) model. The authors then used the PLS algorithm for the determination of caffeine in tea samples from China [23].

Caffeine is consumed daily in coffee, tea, chocolates, cocoa beans, soft drinks, tea leaves, kola nuts, and drugs and has attracted much public and scientific attention over the past few decades [26,27]. The concentration level of caffeine in vivo is a crucial marker of some disorders such as heart disease, insomnia, asthma, kidney malfunction, and carcinogenesis [28], while normal symptoms are fatigue, headache, and muscle pain [26]. It also causes various physiological effects such as central nervous system stimulation, an increase in blood pressure and alertness, relaxation of the bronchial muscle, and gastric acid secretion and can cause some serious diseases including type 2 diabetes mellitus, depression, Alzheimer's disease, Parkinson's disease, stroke risk, liver disease, and some cancers [26,29]. Some studies have shown that an overdose ( $>200 \mathrm{mg} /$ day) of caffeine can cause coma and death, while the lethal dose was considered to be more than $10 \mathrm{~g}$ (about $170 \mathrm{mg} / \mathrm{kg}$ body weight) [26]. Some athletes in various fields of sport [30] use caffeine-containing energy drinks.

Several methods are well documented for the determination and quantification of caffeine in different energy drinks and tea samples, including high performance liquid chromatography (HPLC) [31,32], gas chromatography-mass spectrometry (GC-MS) [33], micellar electrokinetic capillary chromatography (MEKC) [34,35], MEKC with conductivity/photometry detection [35], high-performance thin layer chromatography- electrospray ionization mass spectrometry (HPTLC-ESI/MS) [36], UV-Vis spectrophotometry [37-43], solid phase extraction-high performance liquid chromatography (SPE-HPLC) [44], NIRS [45], square wave voltammetry [46], and microextraction coupled to HPLC [28]. Limited research work has been reported on the quantification of caffeine in tea samples by NIR spectroscopy. In the present study, a calibrated NIRS method and HPLC have been used as complementary techniques for the quantification of caffeine in 25 commercially available tea samples consumed in Oman.

\section{Materials and Methods}

\subsection{Collection and Preparation of the Tea Samples and FT-NIRS Analysis}

Twenty-five different types of commercially available black tea samples were randomly purchased from the local market in Nizwa (Oman) and were properly labeled with codes. The extract of the tea samples was obtained by boiling, at 85 to $90^{\circ} \mathrm{C}$, of $1.5 \mathrm{~g}$ of the dry tea sample in distilled water $(100 \mathrm{~mL})$ for $10 \mathrm{~min}$. After cooling, the tea infusions were filtered through a Whatman filter paper (qualitative, $150 \mathrm{~mm} \varnothing$ ) and then diluted with distilled water up to $10 \%(\mathrm{v} / \mathrm{v})$. Each extract of the tea samples was prepared in triplicates and was used for both NIRS and HPLC analysis. 
Similarly, different concentrations of 45 working standards of caffeine (analytical grade, Sigma-Aldrich) were prepared in tea sample solution by the standard addition method to eliminate the complex texture effect of the tea samples in the range of 1.0 to $100 \mathrm{ppm}$ (all samples in triplicates). All the standard solutions prepared in the tea were then measured using a Frontier NIR spectrophotometer (PerkinElmer, BSEN60825-1:2007, Waltham, MA, United State). Spectra were acquired in absorption mode in the wavenumber range of 10,000 to $4000 \mathrm{~cm}^{-1}$, at a $2 \mathrm{~cm}^{-1}$ resolution using a $0.2 \mathrm{~mm}$ path length of $\mathrm{CaF}_{2}$ sealed cells.

\subsection{Partial Least-Squares Regression Analysis}

The near-infrared (NIR) spectra were split into a training set of $75 \%$ of all the spectral data to build the partial least-squares regression (PLSR) calibration model and a test set of $25 \%$ of all spectral data to externally validate the PLSR calibration model. The test set samples from the training set were randomly selected and were kept aside. The PLSR calibration model was also internally validated, using a full cross-validation procedure that involved the investiagion of the maximum of seven latent variables (LVs). Partial least-squares (PLS) regression is also sometimes referred to as projection to latent structures-or simply PLS-and models both the X-and Y-matrices simultaneously to find the latent (or hidden) variables in $X$ that will best predict the latent variables in $Y$. These PLS components are similar to principal components but will be referred as PLS factors. Before PLSR modeling, unit vector normalization, standard normal variates (SNVs) and first derivatives were used to correct both multiplicative and additive effects of the spectra. Smoothing was used to reduce instrumental noise or background information, and de-trending techniques were performed to reduce the effects of accumulating data sets from a trend. To increase the spectral resolution, the first derivative of the spectra based on the Savitzky-Golay algorithm with 11 smoothing points and a polynomial order of 2 was also performed. Derivatives are commonly used to reduce insignificant baseline signals from samples (Savitzky-Golay, 1964). The precision and optimization of the developed PLSR models were evaluated based on the lowest root mean square error of cross-validation (RMSECV) and the highest value of $R^{2}$ for both calibration and external validation sets. Spectral pretreatments such as unit vector normalization for full spectra were found to represent the best pre-processing spectral transformation.

\subsection{HPLC-DAD Analysis}

For the chromatographic analysis, an HPLC instrument (Agilent Technologies, Tokyo, Japan, 1260) equipped with a C18 column (reverse phase, $3.9 \times 150$ mm, $10 \mu \mathrm{m} 125 \AA$ (Waters; Nova-Pak, Milford, MA, United State of America) was used. The injection volume was $10 \mu \mathrm{L}$ and the column temperature was $38^{\circ} \mathrm{C}$ with a $15 \mathrm{~min}$ running time (stop time) for the caffeine standards and tea samples. The signal of caffeine was monitored at a wavelength of $273 \mathrm{~nm}$ using a diode array detector (DAD) signal. The caffeine stock standard (analytical grade, Sigma-Aldrich, Darmstadt, Hesse, Germany) solutions were prepared by dissolving $0.1 \mathrm{~g}$ of sample in $100 \mathrm{~mL}$ of distilled water. The working standard solutions of caffeine were prepared by suitable dilution from the stock solution, and the stock solution was then stored in the refrigerator for further analysis. Separation of the caffeine was achieved with water-acetonitrile $(85: 15 \mathrm{v} / \mathrm{v})$ with $0.1 \%$ formic acid as the mobile phase at a flow rate of $1 \mathrm{~mL} \mathrm{~min}^{-1}$. All the chemicals, reagents and solvents used were of analytical grade.

\section{Results and Discussion}

\subsection{Near Infrared Spectra of the Caffeine and Tea Samples}

Figure 1 shows the raw (not pre-processed) NIR spectra for all the caffeine standards and the tea samples ranging from 10,000 to $4000 \mathrm{~cm}^{-1}$. 


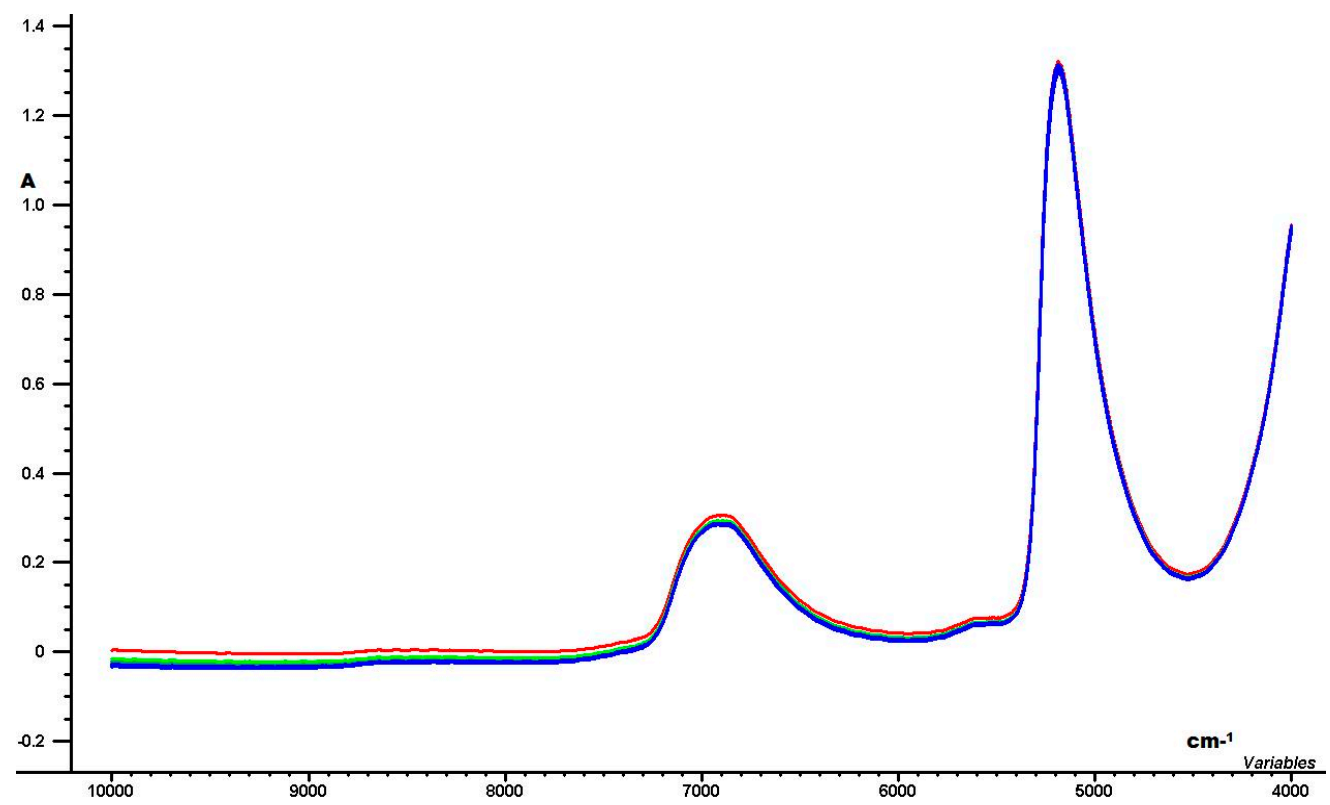

Figure 1. Fourier transform-near infrared (FT-NIR) spectra for all the caffeine standards and tea samples where A is for absorption.

The NIR spectra (Figure 1) are very well organized, but the data are overlapping and hidden inside the broader absorption peaks. In order to correlate the hidden NIR peaks with the variation related to caffiene contents, the multivariate regression method PLSR was used.

Prior to the application of the PLS regression method on the NIR spectral data, spectral transformations such as the standard normal variate (SNV), unit vector normalization (UVN) and first derivative with Savitzky-Golay smoothing were also applied as in Table 1. The pre-processing method was applied to remove noise and undesirable sources of variation from the NIR spectra. The best spectral transformation was chosen as the one with lowest values of root mean square error of cross validation (RMSECV), root mean square error of prediction (RMSEP), least number of factors, and the highest possible value of $\mathrm{R}^{2}$ in the PLS models.

As can be seen from Table 1, the unit vector normalization for the full spectra was the optimal spectral transformation for building the PLS model. 
Table 1. Selection of the best spectral pre-processing. PLS: partial least-squares; RMSECV: root mean square error of cross validation; RMSEP: root mean square error of prediction; SNV: standard normal variate.

\begin{tabular}{|c|c|c|c|c|c|c|}
\hline \multicolumn{4}{|c|}{ PLS Regression } & \multicolumn{2}{|c|}{ PLS Prediction } & \multirow[b]{2}{*}{ No. of Factor } \\
\hline Type of Spectra & Pre-Processing & $\begin{array}{l}\text { RMSECV } \\
\text { (ppm) }\end{array}$ & $\mathbf{R}^{2}$ & $\begin{array}{c}\text { RMSEP } \\
\text { (ppm) }\end{array}$ & $\mathrm{r}^{2}$ & \\
\hline $\begin{array}{c}\text { Full Spectra } \\
\left(4000 \text { to } 10000 \mathrm{~cm}^{-1}\right)\end{array}$ & $\begin{array}{l}\text { Without } \\
\text { pre-processing }\end{array}$ & 1.5 & 0.94 & 2.3 & 0.95 & 5 \\
\hline $\begin{array}{c}\text { Full Spectra } \\
\left(4000 \text { to } 10000 \mathrm{~cm}^{-1}\right)\end{array}$ & $\begin{array}{l}\text { Unit Vector } \\
\text { Normalization }\end{array}$ & 0.03 & 0.99 & 0.08 & 0.97 & 3 \\
\hline $\begin{array}{c}\text { Full Spectra } \\
\left(4000 \text { to } 10000 \mathrm{~cm}^{-1}\right)\end{array}$ & SNV & 0.53 & 0.98 & 1.23 & 0.96 & 5 \\
\hline $\begin{array}{c}\text { Full Spectra } \\
\left(4000 \text { to } 10000 \mathrm{~cm}^{-1}\right)\end{array}$ & SNV & 0.43 & 0.97 & 0.75 & 0.94 & 5 \\
\hline $\begin{array}{c}\text { Full Spectra } \\
\left(4000 \text { to } 10000 \mathrm{~cm}^{-1}\right)\end{array}$ & $\begin{array}{l}\text { First derivation with } \\
11 \text { smoothing points }\end{array}$ & 2.08 & 0.99 & 4.11 & 0.97 & 3 \\
\hline $\begin{array}{c}\text { Spectra } \\
\left(4000 \text { to } 5400 \mathrm{~cm}^{-1}\right)\end{array}$ & $\begin{array}{l}\text { First derivation with } \\
11 \text { smoothing points }\end{array}$ & 1.87 & 0.99 & 1.92 & 0.97 & 3 \\
\hline
\end{tabular}




\subsection{PLS Regression}

In order to determine the unidentified amount of caffeine in different tea samples, the optimized PLS regression model (Figure 2) was built using the training set. The PLS regression model was validated by two methods: the leave one out full cross validation method was used for internal cross validation while building the PLSR method, while the test set was used as an independent set as an external validation tool. Afterwards, validation was applied to tea samples to quantify the amount of caffiene. The results obtained as shown in Table 2 were also cross-verified by a parallel HPLC method.

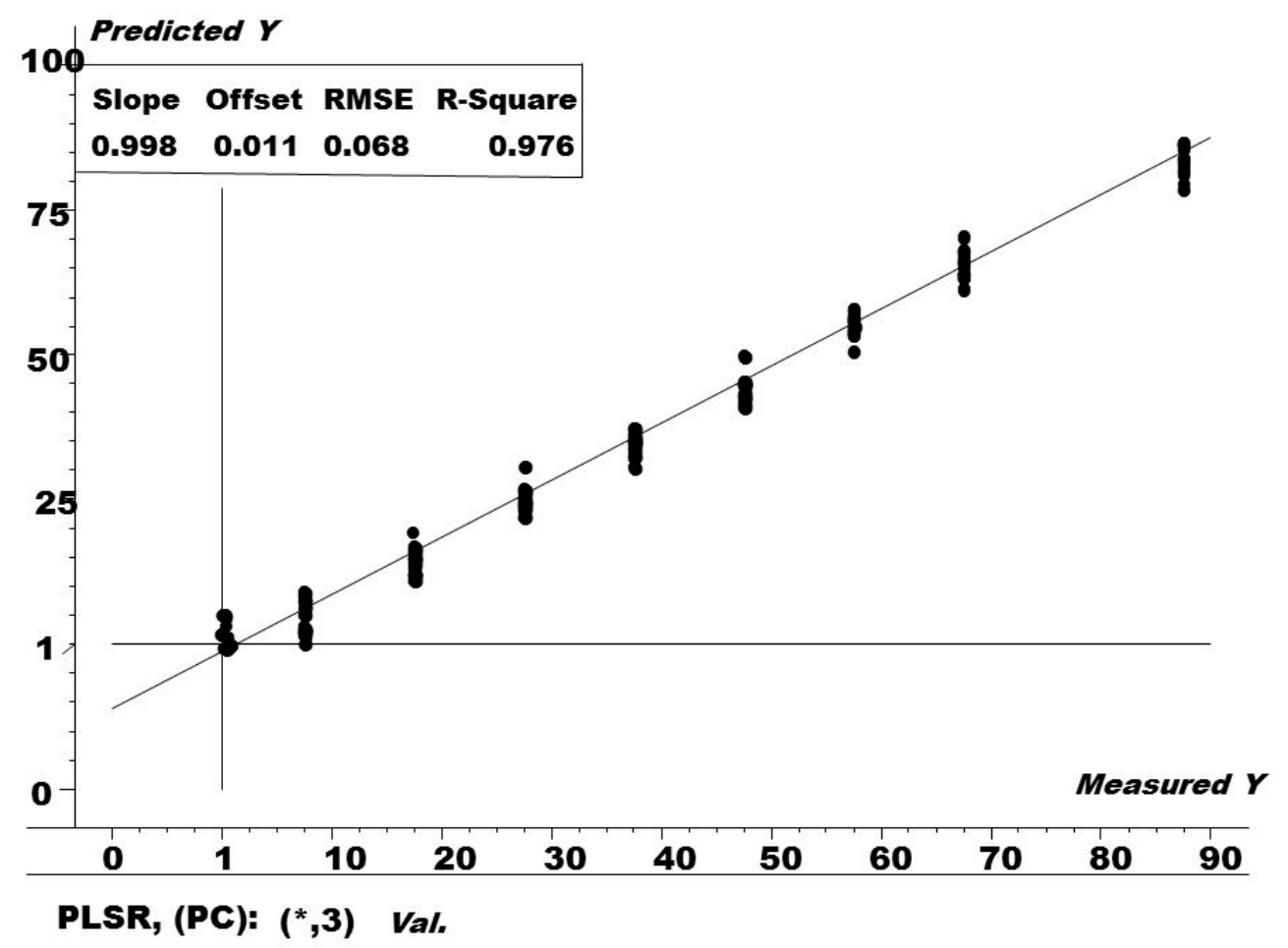

Figure 2. PLS cross-validation plot for the training set. RMSE = root mean square of error, while PLSR $=$ partial least square regression.

The $\mathrm{R}^{2}$ and root mean square error of cross validation (RMSECV) values for the PLS model in Figure 2 were found to be 0.976 and $0.068 \mathrm{ppm}$, respectively. RMSECV is a statistical measure which is mostly used for the prediction ability of the PLS model, using pseudo (external samples) and the leave-one-out procedure. The smaller the value of RMSECV, the better the PLS model is considered, and this is calculated as in Equation (1):

$$
\text { RMSECV }=\sqrt{\frac{\sum_{i=1}^{n}\left(y_{i}-\hat{y}_{i}\right)^{2}}{n}}
$$

where y caped is the forecast (predicted) value, $y_{i}$ is the actual (measured) value by the model, and $n$ is the number of segments (left-out samples in the cross-check process). In our case, as the leave-one-out cross-validation procedure was applied, $n$ equals the number of calibration samples in the training set. A smaller value of RMSECV means a better prediction ability of the PLS model. 


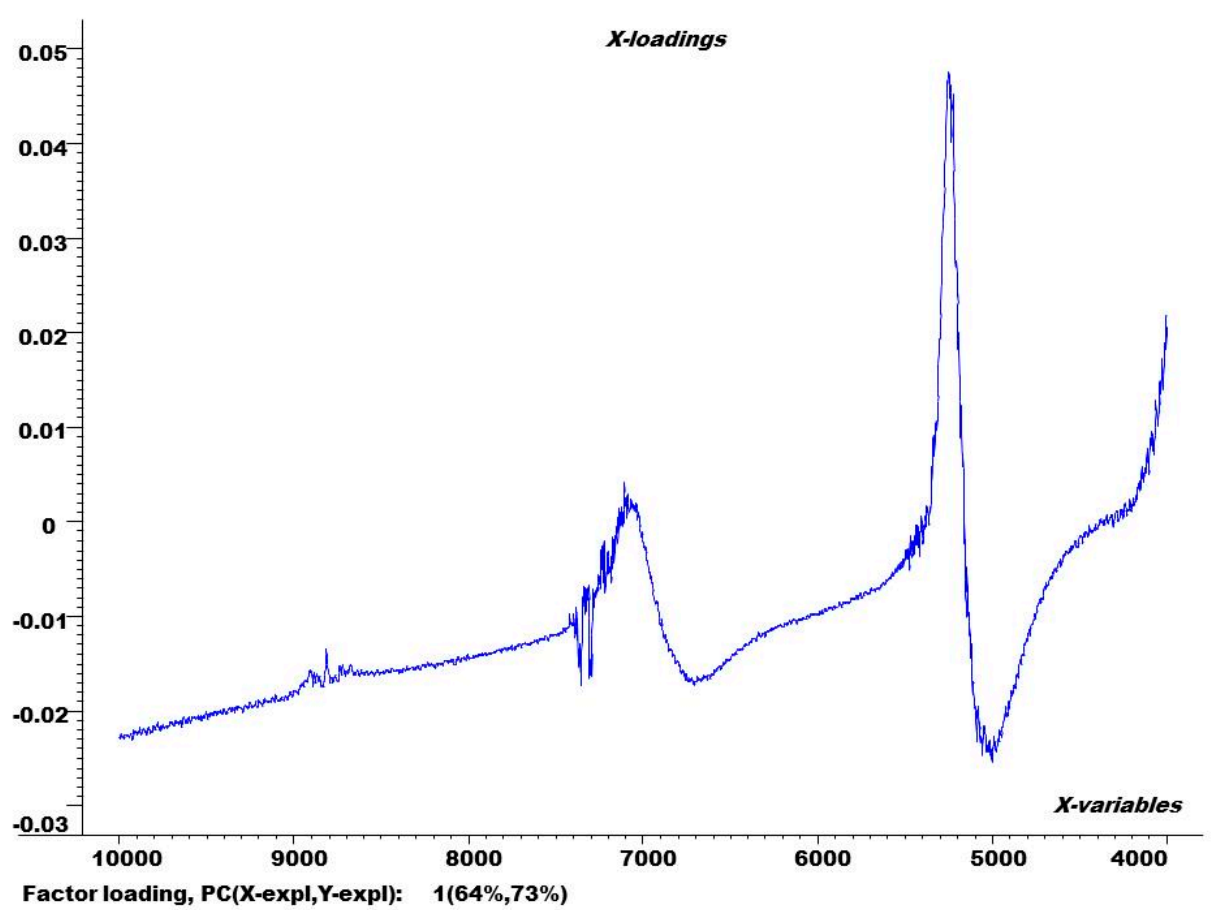

Figure 3. Loading plot for factor 1 of the PLSR model.

Figure 3 determines the loading plot for the first factor of the optimum PLS model. It can be seen that factor 1 provides $64 \%$ and $73 \%$ to the modelling of $X$ (spectra) and $Y$ (concentration of caffeine), respectively. The plot also indicates which spectral variables (wavenumbers) impart more to the construction of the PLS regression model. In this case, characteristic absorption bands related with caffeine can be found at $4444 \mathrm{~cm}^{-1}$ (C-H stretching and C-H deformation, $\left.\mathrm{CH}_{3}\right), 5917 \mathrm{~cm}^{-1}(\mathrm{C}-\mathrm{H}$ stretching first overtone, $\mathrm{CH}_{3}$ ), $4299 \mathrm{~cm}^{-1}$ (all C-H stretching and C-H deformation, $\mathrm{CH}_{2}$ ), $4128 \mathrm{~cm}^{-1}$ (C-H stretching and C-C stretching, $\left.\mathrm{CH}_{2}\right)$, and $4878 \mathrm{~cm}^{-1}\left(\mathrm{~N}-\mathrm{H}\right.$ asymmetric stretching, $\left.\mathrm{CONH}_{2}\right)$. Once the PLS regression model was built, it was then externally validated using the test set $(30 \%$ of the NIR spectral data), as demonstrated in Figure 4.

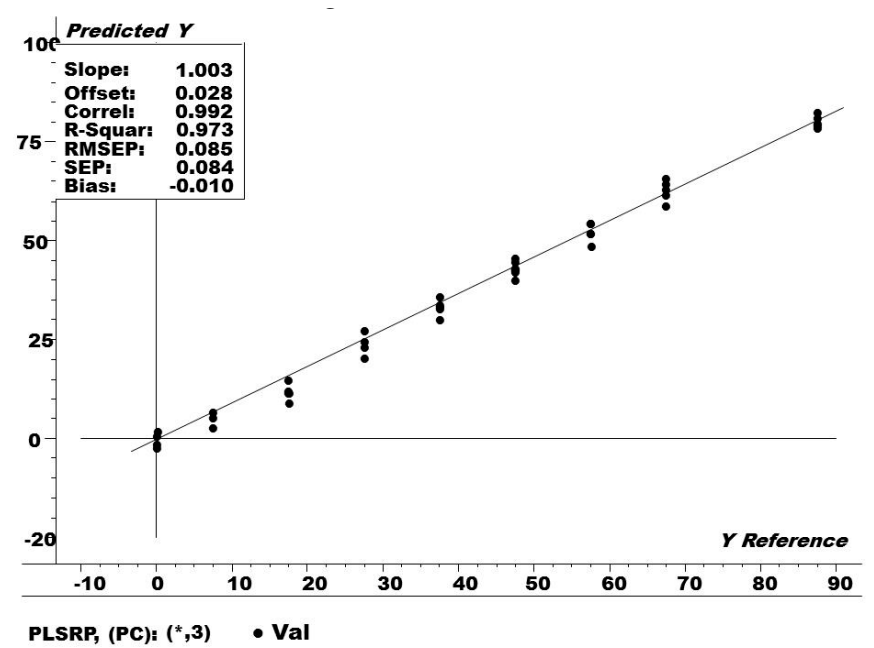

Figure 4. Measured vs predicted PLSR plot for the test set of the caffeine standards. RMSEP $=$ root mean square error of prediction, while PLSP $=$ partial least square regression curve of prediction.

It can be seen that the RMSEP and $\mathrm{r}^{2}$ values (0.08 ppm and 0.97 , respectively) are very good. The RMSEP is a statistical estimator of the average prediction error for future samples (not used when 
building the PLS model). After validation with the test set, the PLS regression model was used for the prediction of the unknown amount of caffeine in the tea samples. The results are displayed in Table 2.

\subsection{HPLC Results}

In parallel, the HPLC technique was also applied to confirm the results achieved by the proposed FTNIR-PLS method. The HPLC chromatograms for both the caffeine standards and tea samples are displayed in Figure S1.

It can be seen that the chromatographic peak at a retention time of $2.07 \mathrm{~min}$ is the peak for the caffeine standard. This was then used to build the univariate standard calibration curve between the peak area of caffeine standards and concentration, as displayed in Figure S2.

It can also be seen from Figure S2 that the standard calibration-based HPLC results have a high correlation $(r=0.987)$. The HPLC calibration curve was used to quantify the amount of caffeine in the tea samples. The results are presented in Table 2.

The contents of caffeine in the 25 tea samples were determined by the proposed method. Among these samples, all varities of Barry's Tea samples $(2.34-2.47 \mathrm{~g} / 100 \mathrm{~g})$ had the highest concentration of caffeine, followed by Society $(2.38 \mathrm{~g} / 100 \mathrm{~g})$ and Tea Special Blend $(2.22 \mathrm{~g} / 100 \mathrm{~g})$. However, trace contents of caffeine were detected in the Lemon Ginger tea samples. The results obtained by both methods can be seen in Table 2.

Table 2. The average content of caffeine in black tea infusions $(g / 100 \mathrm{~g} \pm \mathrm{SD})$, where SD stands for standard deviation).

\begin{tabular}{cccc}
\hline S. No & Sample Name & NIR & HPLC \\
\hline 1 & Decaf Bland Black Tea Bags & $2.45 \pm 0.07$ & $2.47 \pm 0.05$ \\
2 & Classic Bland Tea Bags & $2.43 \pm 0.10$ & $2.46 \pm 0.08$ \\
3 & Irish Breakfast Tea Bags & $2.32 \pm 0.08$ & $2.34 \pm 0.09$ \\
4 & Gold Bland Tea bags & $2.39 \pm 0.08$ & $2.41 \pm 0.01$ \\
5 & Extra strong Black Tea & $1.96 \pm 0.29$ & $1.97 \pm 0.21$ \\
6 & Black Tea Cardamom Bags & $2.01 \pm 0.07$ & $2.03 \pm 0.05$ \\
7 & Yellow Label Black Tea & $2.05 \pm 0.15$ & $2.09 \pm 0.19$ \\
8 & Earl Grey Black Tea Bags & $1.70 \pm 0.15$ & $1.71 \pm 0.12$ \\
9 & Hibiscus Herbal Infusion Bags & $(\mathrm{ND})$ & ND \\
10 & Mint Herbal Infusion Bags & ND & ND \\
11 & Anise Herbal Infusion & Trace & Trace \\
12 & Lemon Ginger Flavored Herbal Infusion & ND & ND \\
13 & Black Tea Blended & $1.73 \pm 0.18$ & $1.74 \pm 0.11$ \\
14 & Green Tea Bags & $2.13 \pm 0.13$ & $2.14 \pm 0.11$ \\
15 & Tea Special Blend & $2.21 \pm 0.05$ & $2.22 \pm 0.04$ \\
16 & Society Tea & $2.36 \pm 0.13$ & $2.38 \pm 0.14$ \\
17 & Society Masala Tea & $2.10 \pm 0.11$ & $2.11 \pm 0.12$ \\
18 & Red label & $2.11 \pm 0.29$ & $2.13 \pm 0.28$ \\
19 & Premium Black & $2.04 \pm 0.03$ & $2.05 \pm 0.04$ \\
20 & Kanan Devan Classic Black & $2.05 \pm 0.09$ & $2.09 \pm 0.06$ \\
21 & Black Loose Tea Gold & $1.35 \pm 0.08$ & $1.37 \pm 0.07$ \\
22 & Green Tea Bags Mint & $1.45 \pm 0.02$ & $1.49 \pm 0.03$ \\
23 & Black Tea & $2.15 \pm 0.32$ & $2.14 \pm 0.31$ \\
24 & Finest Garden Tea & $1.80 \pm 0.03$ & $1.83 \pm 0.02$ \\
25 & Laxative Tea Filter Bags & ND & ND \\
\hline
\end{tabular}

$\mathrm{SD}=$ Standard deviation, $\mathrm{ND}=$ Not detected.

\section{Conclusions}

The results of the proposed study showed that the suggested FT-NIRS-PLSR method has a great deal of potential for routine used for the robust and reproducible analysis of caffeine in different varieties of tea samples. Barry's Tea samples showed a higher concentration than other brands. In addition, this technique does not require expensive solvents and reagents; it may be recommended for 
the precise, rapid and sensitive quantification of caffeine in these products and can also be extended to various beverages, soft drinks, and coffee samples.

Supplementary Materials: The following are available online at http://www.mdpi.com/2304-8158/9/6/827/s1, Figure S1: HPLC chromatograms of all the caffeine standards as well as tea samples at 2.07 min retention time. Figure S2: Standard calibration curve of caffeine for HPLC analysis.

Author Contributions: N.U.R. purchased tea samples, while M.A.-B. and S.A. carried out NIR and HPLC analysis in the laboratory. F.M. and J.H. assisted in NIR experiments and performed statistical analysis. N.U.R. and F.M. wrote the original draft of the manuscript. A.A.-H. and R.B. supervised the whole project and assisted in the reviewing and editing of the manuscript. All the authors have read the final manuscript and approved the submission.

Funding: This research was funded by "The Oman Research Council (TRC), BFP/RGP/CBS/18/011" and "The APC was funded by TRC project.

Acknowledgments: The authors are thankful to the University of Nizwa, Oman for the generous support of this research work.

Conflicts of Interest: The authors declare that they have no conflict of interest concerning the submission of this manuscript.

\section{References}

1. Agelet, L.E.; Hurburgh, C.R., Jr. A tutorial on near infrared spectroscopy and its calibration. Crit. Rev. Anal. Chem. 2010, 40, 246-260. [CrossRef]

2. Dong, W.; Ni, Y.; Kokot, S. A near-infrared reflectance spectroscopy method for direct analysis of several chemical components and properties of fruit, for example, Chinese hawthorn. J. Agric. Food Chem. 2013, 61, 540-546. [CrossRef] [PubMed]

3. León, L.; Kelly, J.D.; Downey, G. Detection of apple juice adulteration using near-infrared transflectance spectroscopy. Appl. Spectrosc. 2005, 59, 593-599. [CrossRef] [PubMed]

4. Chen, L.; Wang, J.; Ye, Z.; Zhao, J.; Xue, X.; Vander Heyden, Y.; Sun, Q. Classification of Chinese honeys according to their floral origin by near infrared spectroscopy. Food Chem. 2012, 135, 338-342. [CrossRef]

5. Al-Harrasi, A.; Rehman, N.U.; Mabood, F.; Albroumi, M.; Ali, L.; Hussain, J.; Hussain, H.; Csuk, R.; Khan, A.L.; Alam, T. Application of NIRS coupled with PLS regression as a rapid, non-destructive alternative method for quantification of KBA in Boswellia sacra. Spectrochim Acta A Mol. Biomol. Spectrosc. 2017, 184, 277-285. [CrossRef] [PubMed]

6. Alpdoğan, G.; Karabina, K.; Sungur, S. Derivative spectrophotometric determination of caffeine in some beverages. Turk. J. Chem. 2002, 26, 295-302.

7. Dinç, E.; Baleanu, D.; Onur, F. Spectrophotometric multicomponent analysis of a mixture of metamizol, acetaminophen and caffeine in pharmaceutical formulations by two chemometric techniques. J. Pharmaceut. Biomed. Anal. 2001, 26, 949-957. [CrossRef]

8. Groisser, D.S. A study of caffeine in tea. I. A new spectrophotometric micro-method. II. Concentration of caffeine in various strengths, brands, blends, and types of teas. Am. J. Clin. Nutr. 1978, 31, 1727-1731. [CrossRef]

9. Grasel, F.; Ferrão, M. A rapid and non-invasive method for the classification of natural tannin extracts by near-infrared spectroscopy and PLS-DA. Anal. Methods 2016, 8, 644-649. [CrossRef]

10. Cen, H.; He, Y. Theory and application of near infrared reflectance spectroscopy in determination of food quality. Trends Food Sci. Tech. 2007, 18, 72-83. [CrossRef]

11. Guo, Z.; Chen, Q.; Chen, L.; Huang, W.; Zhang, C.; Zhao, C. Optimization of informative spectral variables for the quantification of EGCG in green tea using Fourier transform near-infrared (FT-NIR) spectroscopy and multivariate calibration. Appl. Spectrosc. 2011, 65, 1062-1067. [CrossRef] [PubMed]

12. Geladi, P.; Kowalski, B.R. Partial least-squares regression: A tutorial. Anal. Chim. Acta 1986, 185, 1-17. [CrossRef]

13. Khanchi, A.R.; Mahani, M.K.; Hajihosseini, M.; Maragheh, M.G.; Chaloosi, M.; Bani, F. Simultaneous spectrophotometric determination of caffeine and theobromine in Iranian tea by artificial neural networks and its comparison with PLS. Food Chem. 2007, 103, 1062-1068. [CrossRef] 
14. Dou, Y.; Sun, Y.; Ren, Y.; Ju, P.; Ren, Y. Simultaneous non-destructive determination of two components of combined paracetamol and amantadine hydrochloride in tablets and powder by NIR spectroscopy and artificial neural networks. J. Pharmaceut. Biomed. Anal. 2005, 37, 543-549. [CrossRef]

15. Esteban-Diez, I.; González-Sáiz, J.; Pizarro, C. Prediction of sensory properties of espresso from roasted coffee samples by near-infrared spectroscopy. Anal. Chim. Acta 2004, 525, 171-182. [CrossRef]

16. De Maesschalck, R.; Van den Kerkhof, T. Implementation of a simple semi-quantitative near-infrared method for the classification of clinical trial tablets. J. Pharmaceut. Biomed. Anal. 2005, 37, 109-114. [CrossRef]

17. Chen, X.; Wu, J.; Zhou, S.; Yang, Y.; Ni, X.; Yang, J.; Zhu, Z.; Shi, C. Application of near-infrared reflectance spectroscopy to evaluate the lutein and $\beta$-carotene in Chinese kale. J. Food Compos. Anal. 2009, 22, 148-153. [CrossRef]

18. Shibata, K.; Moriyama, M.; Fukushima, T.; Kaetsu, A.; Miyazaki, M.; Une, H. Green tea consumption and chronic atrophic gastritis: A cross-sectional study in a green tea production village. J. Epidemiol. 2000, 10, 310-316. [CrossRef] [PubMed]

19. Setiawan, V.W.; Zhang, Z.F.; Yu, G.P.; Lu, Q.Y.; Li, Y.L.; Lu, M.L.; Wang, M.R.; Guo, C.H.; Yu, S.Z.; Kurtz, R.C. Protective effect of green tea on the risks of chronic gastritis and stomach cancer. Int. J. Cancer 2001, 92, 600-604. [CrossRef]

20. Fujiki, H.; Suganuma, M.; Okabe, S.; Sueoka, E.; Sueoka, N.; Fujimoto, N.; Goto, Y.; Matsuyama, S.; Imai, K.; Nakachi, K. Cancer prevention with green tea and monitoring by a new biomarker, hnRNP B1. Mutat. Res. Fundam. Mol. Mech. Mutagenesis 2001, 480, 299-304. [CrossRef]

21. Jian, L.; Xie, L.P.; Lee, A.H.; Binns, C.W. Protective effect of green tea against prostate cancer: A case-control study in southeast China. Int. J. Cancer 2004, 108, 130-135. [CrossRef] [PubMed]

22. Nakachi, K.; Matsuyama, S.; Miyake, S.; Suganuma, M.; Imai, K. Preventive effects of drinking green tea on cancer and cardiovascular disease: Epidemiological evidence for multiple targeting prevention. Biofactors 2000, 13, 49-54. [CrossRef]

23. Chen, Q.; Zhao, J.; Zhang, H.; Wang, X. Feasibility study on qualitative and quantitative analysis in tea by near infrared spectroscopy with multivariate calibration. Anal. Chim. Acta 2006, 572, 77-84. [CrossRef]

24. Li, D.; Wang, R.; Huang, J.; Cai, Q.; Yang, C.S.; Wan, X.; Xie, Z. Effects and mechanisms of tea regulating blood pressure: Evidences and promises. Nutrients 2019, 11, 1115. [CrossRef] [PubMed]

25. Trevisanato, S.I.; Kim, Y.I. Tea and health. Nutr. Rev. 2000, 58, 1-10. [CrossRef] [PubMed]

26. Tzanavaras, P.D.; Themelis, D.G. Development and validation of a high-throughput high-performance liquid chromatographic assay for the determination of caffeine in food samples using a monolithic column. Anal. Chim. Acta 2007, 581, 89-94. [CrossRef]

27. Seeram, N.P.; Henning, S.M.; Niu, Y.; Lee, R.; Scheuller, H.S.; Heber, D. Catechin and caffeine content of green tea dietary supplements and correlation with antioxidant capacity. J. Agric. Food Chem. 2006, 54, 1599-1603. [CrossRef]

28. Yousefi, S.; Kamankesh, M.; Jazaeri, S.; Attaran, A.; Mohammadi, A. A simple, effective and highly sensitive analytical method used for the determination of caffeine in tea and energy drink samples, and method optimization using a central composite design. Anal. Methods 2017, 9, 1665-1671. [CrossRef]

29. Butt, M.S.; Sultan, M.T. Coffee and its consumption: Benefits and risks. Crit. Rev. Food Sci. Nutr. 2011, 51,363-373. [CrossRef]

30. Reissig, C.J.; Strain, E.C.; Griffiths, R.R. Caffeinated energy drinks-A growing problem. Drug Alcohol Depend. 2009, 99, 1-10. [CrossRef]

31. Zuo, Y.; Chen, H.; Deng, Y. Simultaneous determination of catechins, caffeine and gallic acids in green, Oolong, black and pu-erh teas using HPLC with a photodiode array detector. Talanta 2002, 57, 307-316. [CrossRef]

32. Srdjenovic, B.; Djordjevic-Milic, V.; Grujic, N.; Injac, R.; Lepojevic, Z. Simultaneous HPLC determination of caffeine, theobromine, and theophylline in food, drinks, and herbal products. J. Chromatogr. Sci. 2008, 46, 144-149. [CrossRef] [PubMed]

33. Shrivas, K.; Wu, H.F. Rapid determination of caffeine in one drop of beverages and foods using drop-to-drop solvent microextraction with gas chromatography/mass spectrometry. J. Chromatogr. A 2007, 1170, 9-14. [CrossRef] 
34. Injac, R.; Srdjenovic, B.; Prijatelj, M.; Boskovic, M.; Karljikovic-Rajic, K.; Strukelj, B. Determination of caffeine and associated compounds in food, beverages, natural products, pharmaceuticals, and cosmetics by micellar electrokinetic capillary chromatography. J. Chromatogr. Sci. 2008, 46, 137-143. [CrossRef]

35. Vochyánová, B.; Opekar, F.; Tůma, P. Simultaneous and rapid determination of caffeine and taurine in energy drinks by MEKC in a short capillary with dual contactless conductivity/photometry detection. Electrophoresis 2014, 35, 1660-1665. [CrossRef]

36. Aranda, M.; Morlock, G. New method for caffeine quantification by planar chromatography coupled with electropray ionization mass spectrometry using stable isotope dilution analysis. Rapid Commun. Mass Spectrom. 2007, 21, 1297-1303. [CrossRef]

37. Belay, A.; Ture, K.; Redi, M.; Asfaw, A. Measurement of caffeine in coffee beans with UV/vis spectrometer. Food Chem. 2008, 108, 310-315. [CrossRef]

38. Amos-Tautua, W.; Diepreye, E. Ultra-violet spectrophotometric determination of caffeine in soft and energy drinks available in Yenagoa, Nigeria. Adv. J. Food Sci. Tech. 2014, 6, 155-158. [CrossRef]

39. Atomssa, T.; Gholap, A. Characterization of caffeine and determination of caffeine in tea leaves using uv-visible spectrometer. Afr. J. Pure Appl. Chem. 2011, 5, 1-8.

40. Sethuraman, S.; Radhakrishnan, K. Analytical method development and validation of caffeine in tablet dosage form by using UV-spectroscopy. Int. J. Novel Trends Pharm. Sci. 2013, 3, 82-86.

41. Pelozo, M.I.d.G.; Cardoso, M.L.C.; Mello, J.C.P.D. Spectrophotometric determination of tannins and caffeine in preparations from Paullinia cupana var. sorbilis. Braz. Arch. Biol. Technol. 2008, 51, 447-451. [CrossRef]

42. Maidon, A.; Mansoer, A.O.; Sulistyarti, H. Study of various solvents for caffeine determination using UV spectrophotometeric. J. Appl. Sci. Res. 2012, 8, 2439-2442.

43. Sinija, V.R.; Mishra, H.N. FT-NIR spectroscopy for caffeine estimation in instant green tea powder and granules. LWT Food Scie. Technol. 2009, 42, 998-1002. [CrossRef]

44. Mumin, M.A. Determination and characterization of caffeine in tea, coffee and soft drinks by solid phase extraction and high performance liquid chromatography (SPE-HPLC). Mal. J. Chem. 2006, 8, 45-51.

45. Lee, M.S.; Hwang, Y.S.; Lee, J.; Choung, M.G. The characterization of caffeine and nine individual catechins in the leaves of green tea (Camellia sinensis L.) by near-infrared reflectance spectroscopy. Food Chem. 2014, 158, 351-357. [CrossRef]

46. Tefera, M.; Geto, A.; Tessema, M.; Admassie, S. Simultaneous determination of caffeine and paracetamol by square wave voltammetry at poly (4-amino-3-hydroxynaphthalene sulfonic acid)-modified glassy carbon electrode. Food Chem. 2016, 210, 156-162. [CrossRef]

(C) 2020 by the authors. Licensee MDPI, Basel, Switzerland. This article is an open access article distributed under the terms and conditions of the Creative Commons Attribution (CC BY) license (http://creativecommons.org/licenses/by/4.0/). 